\title{
O PROJETO QUEIXADINHA: A MORBIDADE E O CONTROLE DA ESQUISTOSSOMOSE EM ÁREA ENDÊMICA NO NORDESTE DE MINAS GERAIS, BRASIL
}

\author{
José Roberto Lambertucci, Rogério Gerspacher-Lara, Rogério A. Pinto-Silva, \\ Márcia M. Barbosa, Rosângela Teixeira, Helena Facury Barbosa, José Carlos \\ Serufo, Dilermando Fazito Rezende, Sandra Costa Drummond e \\ Abdunnabi A.M. Rayes
}

\begin{abstract}
Nos áltimos cinco anos, em uma área endêmica para esquistossomose no nordeste de Minas Gerais, 561 individuos submeteram-se a exames clinico, laboratoriais, ultra-sonografia abdominal e dopplerecocardiografia visando definir a morbidade da doença antes e após o iratamento. Revelaram-se altas a prevalência de esquistossomose $(66,3 \%)$ e de formas graves (9,5\% com baço palpável). A prevalência de indivíduos sem fibrose hepática e com fibrose leve, moderada e intensa ao ullira-som foi de 46,0\%, 19,6\%, 27,6\% e 6,8\%, respectivamente. Vinte um $(39,6 \%)$ de 53 individuos com baço palpável não apresentavam fibrose periportal ao ultrasom. Linfonodos periportais foram identificados em $33,8 \%$ dos individuos examinados $e$ anticorpos anti-KLH no soro de 40,7\%. Observaram-se alterą̧ðes urinárias compativeis com glomerulopatia esquistossomótica em 4,5\% da população e $11,7 \%$ apresentavam achados dopplerecocardiográficos de hipertensão pulmonar. Doze meses após o tratanento da esquistossomose, a prevalência da doença reduziu-se de 66,3\% para 25,0\%. Em Queixadinha, um perfil da morbidade da doença e de sua evolução após o tratamento começa a ser delineado.
\end{abstract}

\footnotetext{
Palavras-chaves: Esquistossomose, Glomerulonefrite. Ultra-som. Fibrose periportal. Hipertensão pulmonar.
}

A esquistossomose representa importante problema de saúde pública no Brasil. Estima-se que 6 a 8 milhões de indivíduos encontram-se infectados pelo Schistosoma mansoni. O Programa de Controle da Esquistossomose implantado no nordeste do Brasil entre 1975 e 1979 deixou a impressão de sucesso, em especial pela redução das formas graves da doença, mas, anotaram-se fracassos em alyumas áreas e na grande maioria o programa não recebeu adequada avaliação ${ }^{4} 92124$.

Em Minas Gerais, implantou-se o programa de controle recentemente com a proposta de controlar a morbidade através do tratamento específico. Vários municípios do nordeste de Minas participam deste trabalho em colaboração com a Fundação Nacional de Saúde e com a Secretaria de Estado da Saúde.

\footnotetext{
Departamento de Clínica Médica. Faculdade de Medicina da Universidade Federal de Minas Gerais. Curso de Pós-Graduaçăo em Medicina Tropical, Belo Horizonte, MG.

Financiado parcialmente pelo CNPq. FNS. Faculdade de Medicina da UFMG, Prefeitura Municipal de Caraí (MG).

Endereço para conrespondéncia: Dr. José Roherto Lambertucci. Curso de Pós-Graduação em Medicina Tropical/FM/UFMG. Av. Alfredo Balena 190, 30130 Bulo Horizonte, MG, Brasil. Recebido para publicação em 27/12/95.
}

Os diversos aspectos da morbidade da doença no campo, antes e após o tratamento, utilizando-se novas técnicas diagnósticas como a ultra-sonografia e a ecocardiografia, mereceram pouca atenção no Brasil. A associação com a hepatite B e a prevalência de alterações urinárias sugestivas de glomerulopatia esquistossomótica também não foram definidas.

Com a municipalização do atendimento, outros desafios se impõem. Como integrar as ações educativas, preventivas e terapêuticas e envolver a própria comunidade na solução dos seus problemas'?

Nos últimos cinco anos, Queixadinha, uma área hiperendêmica para esquistossomose no vale do Jequitinhonha (MG), vem sendo estudada. A comunidade identificou a esquistossomose como problema de saúde prioritário. Seguiram-se reuniōes informativas e educativas com a população e realização de filme sobre a doença com a participação de lideranças locais.

Vários aspectos da morbidade da esquistossomose têm sido estudados em Queixadinha. O estudo encontra-se em andamento e os dados apresentados a seguir resumem observações preliminares. Um perfil começa a se delinear. 
Lambertucci JR, Gerspacher-Lara R, Pinto-Silva RA, Barbosa MM, Teixeira R, Barbosa HF, Serufo JC, Rezende $D F$, Drummond SC, Rayes AAM. O Projeto Queixadinha: a morbidade e o controle da esquistossomose em área endêmica no nordeste de Minas Gerais, Brasil. Revista da Sociedade Brasileira de Medicina Tropical 29:127-135, mar-abr, 1996.

\section{MATERIAL E MÉTODOS}

\section{Caracterização da área e de seus habitantes}

Este trabalho foi planejado como um estudo transversal de campo, realizado em Queixadinha, distrito de Caraí, município da região do médio Jequitinhonha, no nordeste de Minas Gerais.

A sede do município (Caraî) localiza-se a uma altitude de 990 metros. Dista $102 \mathrm{~km}$ de Teófilo Otoni e é unida a esta cidade por um trecho da rodovia Rio-Bahia e por uma estrada não pavimentada de $30 \mathrm{~km}$. Trata-se de região de clima tropical semi-úmido com precipitação anual média próxima a $900 \mathrm{~mm}$.

Queixadinha liga-se à sede do município por uma estrada não pavimentada de $15 \mathrm{~km}$. A localidade é cortada ao meio por um córrego (Figura 1). Só uma casa possui água encanada, de cisterna, e cerca de $95 \%$ da população relatam contato diário com águas naturais. Há cerca de cinco anos foi inaugurada rede de energia elétrica e há iluminação pública no trecho da estrada que corta a localidade.

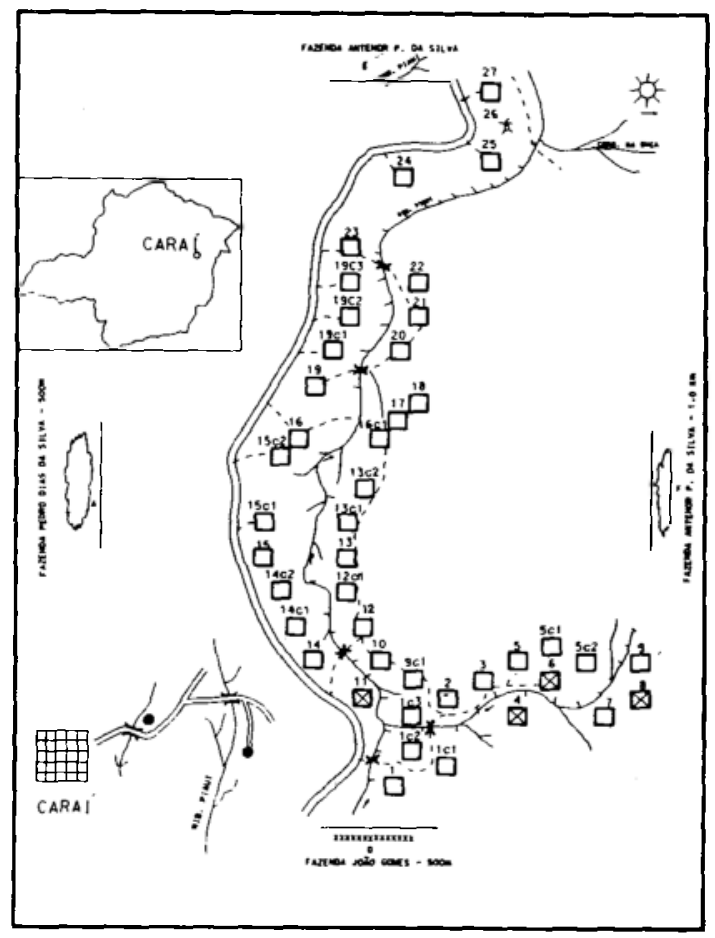

Figura 1 - Desenho esquemático de uma áréa estulada com identificação das casas e dos córregos que cortam a região.
Em Queixadinha, apenas um grupo escolar ministra aulas até a terceira série do primeiro grau. A maioria da população pratica a agricultura de subsistência plantando mandioca, milho e café. No local, não há mineração ou garimpagem e não se planta arroz.

Realizou-se inicialmente o censo da população da localidade. Anotaram-se os números das casas, o número de habitantes, seus nomes completos, idade e sexo. Foram recenseados 570 habitantes, dos quais 561 compareceram ao posto de saúde. A distribuição destes indivíduos por faixa etária encontra-se representada na Figura 2. Quarenta e seis por cento eram brancos, $40,8 \%$ pardos e, $13,2 \%$ pretos.

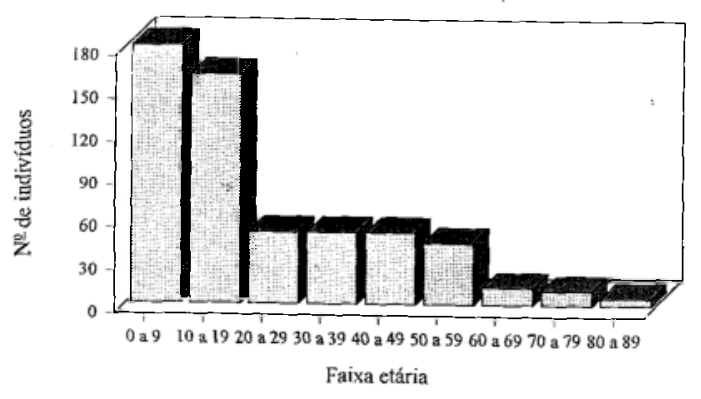

Figura 2 - Distribuiçào dos individuos por jaùa elaria.

\section{Exame clínico}

Todos os pacientes submeteram-se consecutivamenteà anamnese exame clínico. Para cada paciente preencheu-se ficha clínicaepidemiológica padrão. Dentre as informações registradas utilizaram-se aqui as seguintes: idade, sexo, cor, histórià de tratamento para esquistossomose, pressão arterial sistêmica, palpação e mensuração do fígado e baço.

\section{Exame sorológico}

Colheu-se o sangue dos indivíduos, após o exame clínico e, a seguir, armazenou-se o soro a $-20^{\circ} \mathrm{C}$. Os anticorpos IgG anti-KLH (hemocianina do caramujo Megathura crenulata) foram medidos no soro dos indivíduos, de uma das áreas estudadas, utilizandose a técnica de ELISA como descrito em AlvesBrito e cols ${ }^{3}$. 
Lambertucci JR, Gerspacher-Lara R, Pinıo-Silva RA, Barbosa MM, Teixeira R, Barbosa HF, Serufo JC, Rezende $D F$, Drummond SC, Rayes AAM. O Projeto Queixadinha: a morbidade e o controle da esquistossomose em área endêmica no nordeste de Minas Gerais, Brasil. Revista da Sociedade Brasileira de Medicina Tropical 29:127-135. mar-abr, 1996.

\section{Exame parasitológico das fezes}

Foram distribuídos no dia do censo os frascos para coleta de fezes. Para cada habitante, planejouse a coleta de duas amostras de fezes, de dias diferentes, com às quais se prepararam quatro lâminas pela técnica de Kato-Katz.

\section{Exame de urina}

Todos os indivíduos foram instruídos a colher urina do jato médio, de manhã, e entregá-la no posto de saúde o mais cedo possível. Toda a população submeteu-se a uma pesquisa de elementos anormais por meio de fita Comburtest-9 R (Boehringer-Ingelheim) ${ }^{31}$. Aqueles que apresentavam proteinúria isolada ou acompanhada da presença de outros elementos anormais teriam em nossa próxima visita (seis meses mais tarde) a pesquisa de elementos anormais repetida e se submeteriam a uma sedimentoscopia realizada por técnico de laboratório experiente sob nossa supervisão. Dois exames de urina com proteinúria positiva realizados com intervalo de 6 meses foram considerados sugestivos de glomerulopatia.

\section{Exame ultra-sonográfico abdominal}

O exame ecogrático foi sempre realizado pelo mesmo examinador (RAPS) com aparelho portátil Hitachi EUB-200 usando sonda linear eletrônica de $3,5 \mathrm{MHz}$. Os pacientes foram orientados a comparecer em jejum ao exame mas isto nem sempre ocorreu. Mediram-se os diâmetros longitudinal e ântero-posterior dos lobos direito e esquerdo do fígado e o diâmetro kongitudinal do baço. Para definir-se o tamanho normal do baço (até os 18 anos de idade) utilizou-se a seguinte fórmula: baço normal $(\mathrm{cm})=6+1 / 3$ idade $^{33}$.

Definiram-se da seguinte forma os diversos graus de fibrose hepática ao ultra-som ${ }^{11} 13272829$ :

1. Fibrose intensa: presença de espessamento ecogennico (parede com espessura superior a $3 \mathrm{~mm}$ ) em 2/3 ou mais dos ramos portais de segunda ordem visibilizados (fibrose periférica) ou presença de espessamento da parede da veia porta no hilo (mais de $9 \mathrm{~mm}$ ). Superfície hepática rugosa e espessura da parede da vesícula $\geq 6 \mathrm{~mm}$.
2. Fibrose moderada: espessamento de $1 / 3$ a $2 / 3$ dos ramos portais de segunda ordem (parede com espessura $>3 \mathrm{~mm}$ ) ou espessamento ecogênico $(8-9 \mathrm{~mm})$ da veia porta no hilo. Espessura da parede da vesícula $>4 \mathrm{~mm}$.

3. Fibrose leve: presença de espessamento de menos de 1/3 dos ramos portais de segunda ordem (parede $>3 \mathrm{~mm}$ ).

Assim, avaliou-se o grau de fibrose através da observação de todo o fígado.

\section{Exame eletrocardiográfico}

Todos os traçados foram realizados pelo mesmo médico e analisados pelo mesmo cardiologista obedecendo os valores de normalidade como descrito em Barbosa ${ }^{6}$.

\section{Exame dopplerecocardiográfico}

Realizaram-se todos os ecocardiogramas em Queixadinha. Utilizou-se equipamento Esaote SIM 7000 , com mapeamento de fluxos a cores, usandose transdutores combinados para Doppler e imagem, com freqüências de 2,5, 3,5 e 5,0MHz. Todos os estudos envolviam técnicas de ecocardiogratia uni e bidimensional, doppler pulsado, contínuo e mapeamento de fluxos a cores. A monitorização eletrocardiográfica em uma derivação foi realizada e anotada a freqüência cardíaca durante a realização dos exames de todos os casos 612 .

A presença de hipertensão pulmonar foi pesquisada através da avaliação do tempo de aceleração do fluxo pulmonar e do cálculo pelo doppler das pressões pulmonares média e sistólica.

\section{Tratamento}

Todos os indivíduos com exames de fezes positivos para $S$. mansoni foram tratados com a oxamniquine ( $15-20 \mathrm{mg} / \mathrm{kg}$ de peso, dose única. via oral) $)^{1722}$.

\section{Análise estatística}

Para pesquisar a associação entre variáveis categóricas, empregou-se o teste do qui quadrado ou o teste exato de Fisher. A comparação de médias foi precedida da realização do teste de Bartlett para 
Lambertucci JR, Gerspacher-Lara R, Pinto-Silva RA, Barbosa MM, Teixeira R, Barbosa HF, Serufo JC, Rezende $D F$, Drummond SC, Rayes AAM. O Projeto Queixadinha: a morbidade e o controle da esquistossomose em área endêmica no nordeste de Minas Gerais, Brasil. Revista da Sociedade Brasileira de Medicina Tropical 29:127-135, mar-abr, 1996.

testar a homogeneidade das variâncias nos grupos comparados. Se elas diferiam empregava-se o teste de Kruskall-Wallis. Caso contrário o tesie " $t$ " de Student. Para a realização dos cálculos utilizou-se o programa EPI INFO v.5. Para a regressão logística foi empregado o pacote MULTILR.

\section{RESULTADOS}

\section{Exame parasitológico das fezes}

De 561 pacientes incluídos no estudo, 526 foram submetidos a dois exames de fezes. Destes, $349(66,3 \%)$ apresentaram pelo menos um exame positivo para ovos de $S$. mansoni. A prevalência da infecção entre crianças em idade escolar (7-12 anos) foi de $75,4 \%$.

Emuma das cincoáreas estudadas, 96 indivíduos submeteram-se a até quatro exames parasitológicos de fezes. A prevalência de exames positivos para $S$. mansoni variou de $50 \%$ com um exame de fezes, até $91 \%$ quando quatro exames foram realizados.

$\mathrm{Na}$ Figura 3, encontra-se representada a prevalência da infecção entre os indivíduos submetidos a dois exames de fezes em cada faixa etária e pacientes sem exames (perdas).

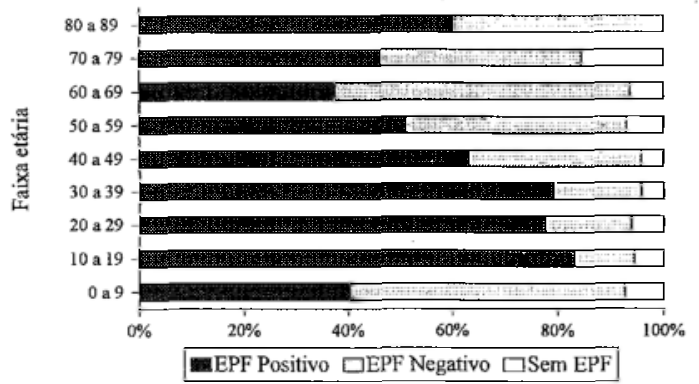

Fugura s-Prevalencia da mjeçàn em cada faba etária e pacientes sem exames (perdas).

A carga parásitaria média da população foi de 138 ovos/grama de fezes. A distribuição por faixa etária encontra-se resumida na Figura 4.

\section{Exame físico}

Trezentos e oitenta e cinco $(72,2 \%)$ indivíduos apresentavam fígado palpável. A média de idade destes pacientes foi de 35 anos com um desvio padrão de 24 e mediana de 38 anos.

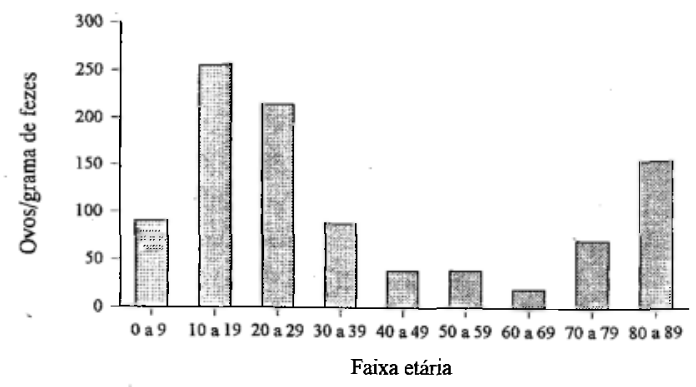

Figura 4 - Distribuição da carga parasitária por faixa etária.

Identificaram-se $53(9,5 \%)$ indivíduos com baço palpável (29 homens e 24 mulheres, com média de idade de 25 anos, desvio padrão de $16 \mathrm{e}$ mediana de 21 anos). Destes, 23 apresentavam fígado com borda lisa e consistência normal, 25 apresentaram consistência aumentada e/ou superfície nodular. Em cinco casos, o fígado não foi palpado.

Dos 431 indivíduos que tiveram suas pressões arteriais sistêmicas registradas, observou-se que $100(23,2 \%)$ apresentaram hipertensão (definida como pressão arterial diastólica $>90 \mathrm{mmHg}$ ou pressão arterial sistólica $>140 \mathrm{mmHg}$ ).

\section{Ultra-sonografia abdominal}

Havia sido planejada a realização de ultrasonografiaem todos os indivíduoscom idade superior a cinco anos e examinaram-se 424 (92,2\%) indivíduos de uma população total de 460 nesta faixa etária. A prevalência de indivíduos sem fibrose, com fibrose leve, moderada e intensa foi de $46,0 \%$, $19,6 \%, 27,6 \%$ e $6,8 \%$, respectivamente.

$\mathrm{Na}$ Figura 5, mostra-se a prevalência de fibrose e seus graus em cada faixa etária. Observa-se que a prevalência de fibrose moderada e intensa aumenta rapidamente até a faixa etária dos 20 aos 30 anos e depois se estabiliza, só diminuindo entre os indivíduos com mais de 70 anos.

De 12 pacientes com fibrose intensa e com colaterais porta evidenciadas ao ultra-som, oito tiveram os seus baços palpados (Figura 6).

Considerando os valores máximos normais do diâmetro esplênico longitudinal, como sendo $8-10 \mathrm{~cm}$ para crianças entre 6 e 12 anos e de $12 \mathrm{~cm}$ para crianças mais velhas e adultos, identificaramse 36 pacientes com esplenomegalia ao ultra-som.

Dos 53 pacientes com esplenomegalia à pal pação 
Lambertucci JR, Gerspacher-Lara R, Pinto-Silva RA, Barbosa MM, Teixeira R, Barbosa HF, Serufo JC, Rezende $D F$, Drummond SC, Rayes AAM. O Projeto Queixadinha: a morbidade e o controle da esquistossomose em área endêmica no nordeste de Minas Gerais, Brasil. Revista da Sociedade Brasileira de Medicina Tropical 29:127-135, mar-abr, 1996.

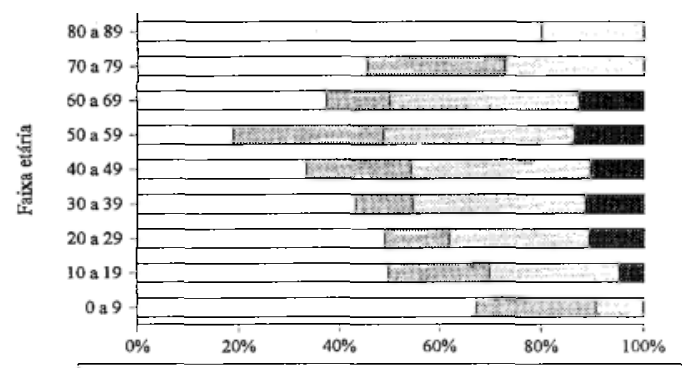

$\square$ Sem Fibrose $\square$ Fibrose Leve $\square$ Fibrose Moderada $\quad$ Fibrose Intensa

Figura 5 - Prevalência da fibrose e seus graus em cada faixa etária.

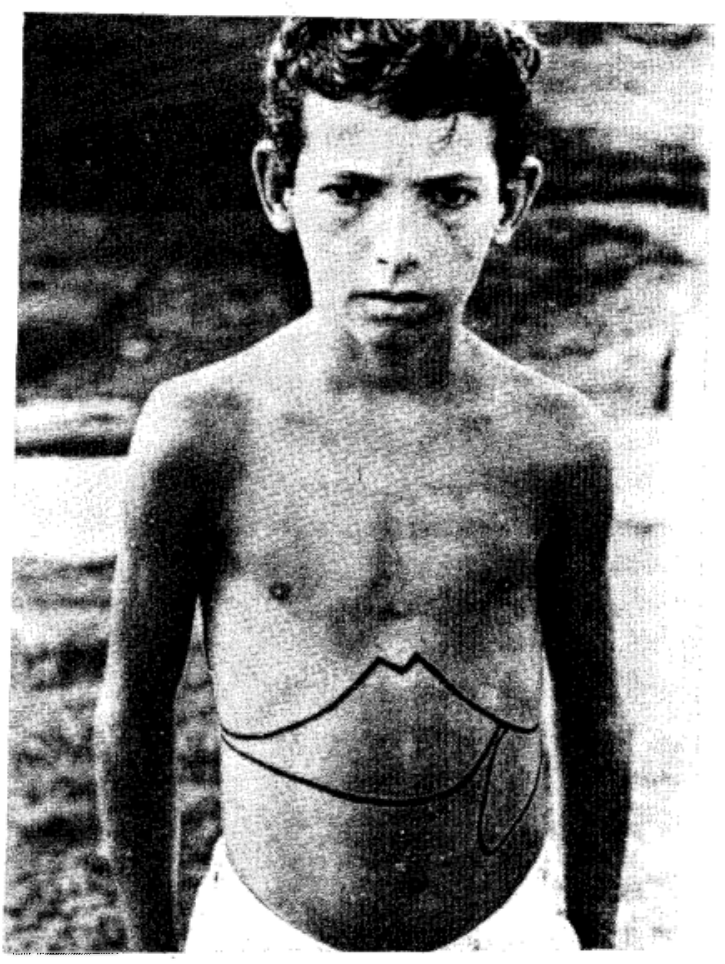

Figura 6 - Criança com hepatoesplenomegalia e fibrose intensa ao ultra-som.

abdominal, 60,3\% apresentavam fibrose ao ultrasom, assim distribuída: fibrose leve (14,7\%), fibrose moderada $(25,0 \%)$, e fibrose intensa $(20,6 \%)$, O tamanho do baço ao ultra-som no grupo com esplenomegalia e sem esplenomegalia à palpação abdominal foi respectivamente de $103,9 \mathrm{~mm} \mathrm{e}$ $67,6 \mathrm{~mm}$ ( $\mathrm{p}<0,001)$.

Em uma das cinco áreas estudadas, procedeu-se a investigação sistemática da presença de linfonodos periportais em todos os indivíduos submetidos ao exame ultra-sonográfico. Quarenta e dois $(33,8 \%)$ de 124 indivíduos examinados pelo ultra-som apresentavam linfonodos periportais. Trinta e um tinham menos de 15 anos de idade e 11 mais de 15 $\operatorname{anos}(\mathrm{p}<0,001)$.

\section{Sorologia para KLH}

Trinta e cinco $(40,7 \%)$ de 86 indivíduos examinados apresentavam títulos elevados no soro de anticorpos IgG anti-KLH. Vinte e dois tinham menos de 15 anos de idade e 13 mais de 15 anos $(p=0,02)$.

\section{Alterações urinárias}

$\mathrm{Na}$ população estudada de 561 indivíduos, observaram-se alterações urinárias compatíveis com glomerulopatia em 25 (4,5\%) casos. Os pacientes foram comparados a população sem proteinúria em relação à idade, sexo, raça, alterações da palpação hepática, presença de baço palpável, pressão arterial sistêmica, carga parasitária, além dos vários parâmetros medidos pelo ultra-som.

Após regressão logística, a única variável associada a alterações urinárias foi a presença de fibrose hepática ao ultra-som.

Três anos ącós o tratamento da esquistossomose, 22 dos 25 indivíduos com alterações urinárias foram reexaminados. Em onze $(50 \%)$ houve regressão das alterações urinárias sugestivas de glomerulopatia esquistossomótica.

\section{Alterações cardiopulmonares}

De 213 pacientes examinados, 25 (11,7\%) apresentavam hipertensão pulmonar bem definida (tempo de aceleração abaixo de 90 milisegundos). A pressão média em artéria pulmonar esteve igual ou acima de $20 \mathrm{mmHg}$ em 54 pacientes e, 43 (80\%) apresentavam ovos de $S$. mansoni nas fezes. A média da pressão pulmonar nos pacientes com hipertensão pulmonar foi de $31,0 \pm 8,8 \mathrm{mmHg}$. Nenhum caso de cor pulmonale foi diagnosticado neste grupo ao exame clínico, eletrocardiográfico ou dopplerecocardiográfico. 
Lambertucci JR, Gerspacher-Lara R, Pinto-Silva RA, Barbosa MM, Teixeira R, Barbosa HF, Serufo JC, Rezende $D F$, Drummond SC, Rayes AAM. O Projeto Queixadinha: a morbidade e o controle da esquislossomose em área endêmica no nordeste de Minas Gerais, Brasil. Revista da Sociedade Brasileira de Medicina Tropical 29:127-135, mar-abr, 1996.

\section{Tratamento da esquistossomose e controle pós- tratamento}

Trezentos e quarenta e nove indivíduos receberam o tratamento para esquistossomose. Dois pacientes apresentaram convulsão. entre 15 e 30 minutos após o tratamento, e recuperaram-se espontaneamente. Outros quatro pacientes, queixaram-se de tonteira de duração efêmera e o restante não apresentou intercorrência digna de nota.

Doze meses depois, repetiu-se o exame de fezes em 186 indivíduos que compareceram ao posto de salíde quando convocados pelos guardas de campo para o controle de cura. Quarenta e sete (25\%) apresentavam ovos de Schistosoma mansoni nas fezes. Houve redução de $40 \%$ na média aritmética do numero de ovos nas fezes nos indivíduos tratados e não curados.

\section{DISCUSSÃO}

\section{Aspectos clínicos, parasitológicos, ultra- sonográlicos e sorológicos.}

A população estudada apresenta alta prevalência de esquistossomose: $66,3 \%$ dos indivíduos apresentaram ovos de $S$. mamsoni nas fezes quando dois exames de fezes foram realizados e $91,0 \% \mathrm{com}$ até quatro exames. Os nossos achados confirmam o acerto do Programa de Controle da Esquistossomose da Fundação Nacional de Saúde, ao tratar toda a população de uma área endêmica quando a prevalência de esquistossomose for maior que $50 \%$ tomando como referência apenas um exame de fezes ${ }^{4}$.

A alta prevalência de esquistossomose na região. dificultou a comparação dos vários aspectos da morbidade entre os grupos positivo e negativo para esquistossomose porque o grupo negativo poderia ser falsamente negativo. Foi elevada, como esperado, a prevalência de formas graves $(9,5 \%$ dos indivíduos apresentavam baço palpável e $34,5 \%$ fibrose periportal moderada ou intensa ao ultrasom).

Fibrose hepática foi evidenciada ao ultra-som em $32(60,3 \%)$ dos 53 pacientes com baço palpável. Em $21(39,6 \%)$ indivíduos o aumento do baço deve ser explicado por outro motivo que não a esquistossomose em sua forma hepatoesplênica e isto certamente apresenta implicações importantes na valorização de estudos anteriores que consideravam baço palpável em área endêmica para esquistossomose como representativo da forma grave da doença ${ }^{23}$.

Algumas explicações são possíveis: 1) nem todo baço palpável significa baço aumentado de tamanho ou sinal de doença atual ${ }^{2} 725$. Em alguns estudos, os autores palparam até $10 \%$ dos baços considerados normais ${ }^{32}$; 2) outras doenças que causam aumento do baço podem passar despercebidas como, hepatites virais, mononucleose, toxoplasmose, esquistossomose aguda, calazar, cirrose hepática alcoólica, entre outras.

De agora em diante, para identificar-se com maior critério indivíduos com esquistossomose hepatoesplênica, torna-se necessário combinar os achados do exame clínico com os achados ultrasonográficos. Esta nova postura, se adotada, exigirá reavaliação dos estudos clínicos, epidemiológicose imunológicos já realizados no campo.

Quatro pacientes com fibrose periportal intensa e colaterais porta identificadas ao ultra-som não apresentavam baço palpável. Esquistossomose hepatoesplênica pode ocorrer sem hepatoesplenomegalia ${ }^{16}{ }^{30}$, mas os nossos dados revelam pela primeira vez a importância deste achado no campo com suas conseqüências na análise da morbidade da doença em área endêmica. O significado da fibrose leve ao ultra-som, não é conhecido. Vale dizer, outras doenças, que não a esquistossomose, podem apresentar-se com espessamento periportal discreto ${ }^{1927}$.

Os valores normais para o tamanho do baço ao ultra-som (aqui calculado baseando-se em estudo realizado nos Estados Unidos) e dos lobos direito e esquerdo do fígado precisam ser estabelecidos no Brasil em regiões não endêmicas para esquistossomose ${ }^{33}$.

O significado de linfonodos periportais aumentados de tamanho ao ultra-som abdominal, mais freqüente em crianças de uma área endêmica para esquistossomose, nãoéconhecido. Linfonodos periportais têm sido descritos em outras doenças, como as hepatites virais por exemplo. Como os linfonodos observados em nosso estudo apresentam aspecto semelhante ao observado em pacientes com esquistossomose mansoni aguda, esta relação deverá ser investigada em outros estudos de campo ${ }^{19}$.

A presença de anticorpos anti-KLH no soro de 
LambertucciJR, Gerspacher-Lara R, Pinto-Silva RA, Barbosa MM, Teixeira R, Barbosa HF, Serufo JC, Rezende $D F$, Drummond SC, Rayes AAM. O Projeto Queixadinha: a morbidade e o controle da esquistossomose em área endêmica no nordeste de Minas Gerais, Brasil. Revista da Sociedade Brasileira de Medicina Tropical 29:127-135, mar-abr, 1996.

$40,7 \%$ dos indivíduos, significativamente mais freqüente em crianças menores de 15 anos de idade, também merece confirmação em outros estudos. A presença de títulos elevados de anticorpos antiKLH tem sido considerada útil para o diagnóstico sorológico da esquistossomose em sua fase aguda ${ }^{3}$. $\mathrm{Na}$ experiência de alguns autores, os títulos destes anticorpos não retornaram aos valores normais um ano após o tratamento da esquistossomose e outros não observaram alteração dos títulos até três anos após o tratamento ${ }^{4}$. Os indivíduos com linfonodos aumentados de tamanho em nosso estudo, tiveram níveis de anticorpos anti-KLH mais elevados no soro, mas a diferença não revelou-se estatisticamente significativa quando comparada com os indivíduos sem linfonodos ao ultra-som.

\section{Alterações urinárias}

Houve forte associação entre a presença de espessamento periportal ao ultra-som e a presença de alterações urinárias compatíveis com glomerulopatia esquistossomótica. A prevalência de proteinúria cresce com o grau de fibrose 820 2831 .

Admitindo-se a hipótese de que a chance de que um indivíduo com esquistossomose apresente glomerulopatia cresce de modo contínuo com a gravidade da lesão hepática, importa verificar se ela contradiz dados obtidos nos trabalhos anteriores. Lehman e $\operatorname{cols}^{23}$ não puderam demonstrar que as alterações urinárias fossem mais freqüentes em esquistossomóticos hepatoesplênicos. É provável que muitos pacientes com esplenomegalia em sua casuística não apresentassem a forma hepatoesplênica da esquistossomose.

Bina e cols $s^{8}$ analisaram uma amostra que incluía um número grande de pacientes hepatoesplênicos e estes indivíduos foram pareados com portadores da forma hepatointestinal, constituindo-se assim uma amostra semelhante às hospitalares. Foi então possível, observar uma diferença significativa entre a prevalência de proteinúria num e noutro grupo. Rabello e cols ${ }^{31}$ estudaram uma amostra pequena em área com prevalência de fibrose periportal provavelmente inferior à observada em Queixadinha. O número de casos identificado foi muito pequeno.

Parece, portanto, que a hipótese de que o risco de que surja glomerulopatia aumenta de modo contínuo, à medida que se agrava a lesão hepática, é coerente com o resultado de todos os trabalhos que abordaram a questão. O tratamento da esquistossomose parece levar à regressão das alterações urinárias abservadas em pacientes de área endêmica para esquistossomose.

\section{Alterações cardiopulmonares}

Esta é a primeira vez em que a dopplerecocardiografia é utilizada no Brasil para avaliar, em área endêmica. o envolvimento cardiopulmonar na esquistossomose. O encontro de hipertensão pulmonar bem detinida em $11,7 \%$ dos casos se aproxima do que foi observado por outros autores. Guimarães, por exemplo, estudando 141 pacientes com esquistossomose hepatoesplênica e utilizando o cateterismo cardiopulmonar anotou hipertensão pulmonar em $13 \%$ dos casos e apenas três pacientes apresentavam cor pulmonale ${ }^{12}$.

Em Queixadinha, 34,5\% dos indivíduos apresentam fibrose hepática moderada ou intensa, mas não se observou relação entre a presença de fibrose ao ultra-som e hipertensão pulmonar. Cavalcanti e cols ${ }^{10}$ admitem a existência de hipertensão pulmonar na ausência da forma hepatoesplênica.

Definida a população com envolvimento pulmonar em Queixadinha, cumpre avaliar a evolução da hipertensão pulmonar após o tratamento clínico. O estudo dopplerecocardiogrático deve também ser repetido em área não endêmica para esquistossomose para melhor definir a relação entre esquistossomose e hipertensão pulmonar em área endêmica.

\section{Tratamento da esquistossomose e controle pós- tratamento}

O número de pacientes examinados, 12 meses após o tratamento, foi pequeno e deverá ser completado na próxima visita a Queixadinha. No grupo examinado houve redução da prevalência de $66,3 \%$, antes do tratamento, para $25,0 \%$ após o tratamento e redução de $40 \%$ na carga parasitária nos casos não curados. Os resultados parecem satisfatórios, mas demonstram a necessidade de repetir-se o tratamento para baixar a prevalência da doença para menos de $10 \% 141517$. 

endêmica no nordeste de Minas Gerais, Brasil. Revista da Sociedade Brasileira de Medicina Tropical 29:127-135, mar-abr, 1996 :

\section{Tratamento da esquistossomose e controle pós- tratamento}

Trezentos e quarenta e nove indivíduos receberam otratamento para esquistossomose. Dois pacientes apresentaram convulsão, entre 15 e 30 minutos após o tratamento, e recuperaram-se espontaneamente. Outros quatro pacientes, queixaram-se de tonteira de duração efêmera e o restante não apresentou intercorrência digna de nota.

Doze meses depois, repetiu-se o exame de fezes em 186 individuos que compareceram ao posto de saúde quando convocados pelos guardas de campo para o controle de cura. Quarenta e sete $(25 \%)$ apresentavam ovos de Schistosoma mansoni nas fezes. Houve redução de $40 \%$ na média aritmética do número de ovos nas fezes nos indivíduos tratados e não curados.

\section{DISCUSSÃO}

\section{Aspectos clínicos, parasitológicos, ultra-} sonográficos e sorológicos.

A população estudada apresenta alta prevalência de esquistossomose: $66,3 \%$ dos indivíduos apresentaram ovos de $S$. mansoni nas fezes quando dois exames de fezes foram realizados e $91,0 \% \mathrm{com}$ até quatro exames. Os nossos achados confirmam o acerto do Programa de Controle da Esquistossomose da Fundação Nacional de Saúde, ao tratar toda a população de uma área endêmica quando a prevalência de esquistossomose for maior que $50 \%$ tomando como referência apenas um exame de fezes ${ }^{4}$.

A alta prevalência de esquistossomose na região, dificultou a comparação dos vários aspectos da morbidade entre os grupos positivo e negativo para esquistossomose porque o grupo negativo poderia ser falsamente negativo. Foi elevada, como esperado, a prevalência de formas graves $(9,5 \%$ dos indivíduos apresentavam baço palpável e $34,5 \%$ fibrose periportal moderada ou intensa ao ultrasom).

Fibrose hepática foi evidenciada ao ultra-som em $32(60,3 \%)$ dos 53 pacientes com baço palpável. Em $21(39,6 \%)$ indivíduos o aumento do baço deve ser explicado por outro motivo que não a esquistossomose em sua forma hepatoesplenica e isto certamente apresenta implicações importantes na valorização de estudos anteriores que consideravam baço palpável em área endêmica para esquistossomose como representativo da forma grave da doença ${ }^{23}$.

Algumas explicações são possíveis: 1) nem todo baço palpável significa baço aumentado de tamanho ou sinal de doença atual ${ }^{2} 725$. Em alguns estudos, os autores palparam até $10 \%$ dos baços considerados normais ${ }^{32}$; 2) outras doenças que causam aumento do baço podem passar despercebiclas como, hepatites virais, mononucleose, toxoplasmose, esquistossomose aguda, calazar, cirrose hepática alcoólica, entre outras.

De agora em diante, para identificar-se com maior critério indivíduos com esquistossomose hepatoesplênica, torna-se necessário combinar os achados do exame clínico com os achados ultrasonográficos. Esta nova postura, se adotada, exigirá reavaliação dos estudos clínicos, epidemiológicose imunológicos já realizados no campo.

Quatro pacientes com fibrose periportal intensa e colaterais porta identificadas ao ultra-som não apresentavam baço palpável. Esquistossomose hepatoesplênica pode ocorrer sem hepatoesplenomegalia ${ }^{160}$, mas os nossos dados revelam pela primeira vez a importância deste achado no campo com suas conseqüências na análise da morbidade da doença em área endêmica. O significado da fibrose leve ao ultra-som, não é conhecido. Vale dizer, outras doenças, que não a esquistossomose, podem apresentar-se com espessamento periportal discreto ${ }^{19} 27$.

Os valores normais para o tamanho do baço ao ultra-som (aqui calculado baseando-se em estudo realizado nos Estados Unidos) e dos lobos direito e esquerdo do fígado precisam ser estabelecidos no Brasil em regiões não endêmicas para esquistossomose ${ }^{33}$.

O significado de linfonodos periportais aumentados de tamanho ao ultra-som abdominal, mais freqüente em crianças de uma área endêmica para esquistossomose, não é conhecido. Linfonodos periportais têm sido descritos em outras doenças, como as hepatites virais por exemplo. Como os linfonodos observados em nosso estudo apresentam aspecto semelhante ao observado em pacientes com esquistossomose mansoni aguda, esta relaçãodeverá ser investigada em outros estudos de campo ${ }^{19}$.

A presença de anticorpos anti-KLH no soro de 
Lambertucci JR, Gerspacher-Lara R, Pinto-Silva RA, Barbosa MM, Teixeira R, Barbosa HF, Serufo JC, Rezende $D F$, Drummond SC, Rayes AAM. O Projeto Queixadinha: a morbidade e o controle da esquistossomose em área endênica no nordeste de Minas Gerais, Brasil. Revista da Sociedade Brasileira de Medicina Tropical 29:127-135, mar-abr, 1996.

$40,7 \%$ dos indivíduos, significativamente mais freqüente em crianças menores de 15 anos de idade, também merece confirmação em outros estudos. A presença de títulos elevados de anticorpos antiKLH tem sido considerada útil para o diagnóstico sorológico da esquistossomose em sua fase aguda ${ }^{3}$. $\mathrm{Na}$ experiência de alguns autores, os títulos destes anticorpos não retornaram aos valores normais um ano após o tratamento da esquistossomose e outros não observaram alteração dos títulos até três anos após o tratamento ${ }^{4}$. Os indivíduos com linfonodos aumentados de tamanho em nosso estudo, tiveram níveis de anticorpos anti-KLH mais elevados no soro, mas a diferença não revelou-se estatisticamente significativa quando comparada com os indivíduos sem linfonodos ao ultra-som.

\section{Alterações urinárias}

Houve forte associação entre a presença de espessamento periportal ao ultra-som e a presença de alterações urinárias compatíveis com glomerulopatia esquistossomótica. A prevalência de proteinúria cresce com o grau de fibrose ${ }^{1820}$ 2831 .

Admitindo-se a hipótese de que a chance de que um indivíduo com esquistossomose apresente glomerulopatia cresce de modo contínuo com a gravidade da lesão hepática, importa verificar se ela contradiz dados obtidos nos trabalhos anteriores. Lehman e cols ${ }^{23}$ não puderam demonstrar que as alterações urinárias fossem mais freqüentes em esquistossomóticos hepatoesplênicos. É provável que muitos pacientes com esplenomegalia em sua casuística não apresentassem a forma hepatoesplênica da esquistossomose.

Bina e cols ${ }^{8}$ analisaram uma amostra que incluía um número grande de pacientes hepatoesplênicos e estes indivíduos foram pareados com portadores da forma hepatointestinal, constituindo-se assim uma amostra semelhante às hospitalares. Foi então possivel, observar uma diferença significativa entre a prevalência de proteinúria num e noutro grupo. Rabello e cols ${ }^{31}$ estudaram uma amostra pequena em área com prevalência de fibrose periportal provavelmente in ferior à observada em Queixadinha. O número de casos identificado foi muito pequeno.

Parece, portanto, que a hipótese de que o risco de que surja glomerulopatia aumenta de modo contínuo, à medida que se agrava a lesão hepática, é coerente com o resultado de todos os trabalhos que abordaram a questão. O tratamento da esquistossomose parece levar à regressão das alterações urinárias abservadas em pacientes de área endêmica para esquistossomose.

\section{Alterações cardiopulmonares}

Esta é a primeira vez em que a dopplerecocardiografia é utilizada no Brasil para avaliar, em área endêmica, o envolvimento cardiopulmonar na esquistossomose. O encontro de hipertensão pulmonar bem definida em $11,7 \%$ dos casos se aproxima do que foi observado por outros autores. Guimarães, por exemplo, estudando 141 pacientes com esquistossomose hepatoesplênica e utilizando o cateterismo cardiopulmonar anotou hipertensão pulmonar em $13 \%$ dos casos e apenas três pacientes apresentavam cor pulmonale ${ }^{12}$.

Em Queixadinha, 34,5\% dos indivíduos apresentam fibrose hepática moderada ou intensa, mas não se observou relação entre a presença de fibrose ao ultra-som e hipertensão pulmonar. Cavalcanti e cols ${ }^{10}$ admitem a existência de hipertensão pulmonar na ausência da forma hepatoesplênica.

Definida a população com envolvimento pulmonar em Queixadinha, cumpre avaliar a evolução da hipertensão pulmonar após o tratamento clínico. O estudo dopplerecocardiográfico deve também ser repetido em área não endêmica para esquistossomose para melhor definir a relação entre esquistossomose e hipertensão pulmonar em área endêmica.

\section{Tratamento da esquistossomose e controle pós- tratamento}

O número de pacientes examinados, 12 meses após o tratamento, foi pequeno e deverá ser completado na próxima visita a Queixadinha. No grupo examinado houve redução da prevalência de $66,3 \%$, antes do tratamento, para $25,0 \%$ após o tratamento e redução de $40 \%$ na carga parasitária nos casos não curados. Os resultados parecem satisfatórios, mas demonstram a necessidade de repetir-se o tratamento para baixạr a prevalência da doença para menos de 10\%141517. 
Lambertucci JR, Gerspacher-Lara R, Pinto-Silva RA, Barbosa MM, Teixeira R, Barbosa HF, Serufo JC, Rezende $D F$, Drummond SC, Rayes AAM. O Projeto Queixadinha: a morbidade e o controle da esquistossomose em área endêmica no nordeste de Minas Gerais, Brasil. Revista da Sociedade Brasileira de Medicina Tropical 29:127-135, mar-abr, 1996.

\section{SUMMARY}

In an endemic are a for schistosomiasis inthe northeast of the state of Minas Gerais in Brazil 516 individnals have been submitted to clinical and laboratory examination, ultrasonography of the abdomen and dopplerecocardiography in order to define the morbidity of schistosomiasis before and afier treatment. A high prevalence of schistosomiasis (66.3\%) and of severe disease $(9.5 \%$ with palpable spleens) were recorded. Ulirasonography classified liver periportal fibrosis as light (19.4\%), moderate (27.6\%) and intense (6.8\%), and $46.0 \%$ presented no periportal fibrosis. Twenty one out of the 53 individuals (39.6\%) with palpable spleens did not present liver fibrosis on ultrasound. Periportal tymph nodes were described in $33.8 \%$ of the population and anti-KLH antibodies were found in the serum of 40.7\%. Urinary alterations compatible with the glomerulopathy of schistosomiasis were observed in $4.5 \%$ of the population, and $11.7 \%$ of the individuals examined by dopplerecocardiograply had pulmonary hypertension. Twelve months after treatment for schistosomiasis the prevalence of the disease dropped from $66.3 \%$ to $25.0 \%$. In Queixadinha, a profile of the morbidity of schistosomiasis has just been established.

Key-words: Schistosomiasis. Glomerulonephritis. Ultrasound. Periportal fibrosis. Pulmonary/hypertension.

\section{AGRADECIMENTOS}

Os autores agradecem à colaboração dos Prefeitos de Caraí (MG): José Maria Ribeiro e Leopoldino José Ribeiro, e do Secretário da Saúde de Caraí (MG) José Geraldo Vieira de Souza. Os técnicos de laboratório José Maria Bernardes (UFMG), Silvana Romano da Silva (UFMG) e Sebastião P. Santos (FNS). Os guardas de campo Ludgério Rodrigues Neto, João Vanderley Magalhaes Ribeiro e Gilmar Soares dos Santos (FNS). O acadêmico de medicina Sérgio L. Murta (UFMG).

\section{REFERÊNCIAS BIBLIOGRÁFICAS}

1. Abensur H, Nussenzweig LB, Saldanha LB, Pestalozzi MSC, Barros MT, Marcondes M, Barros RT. Nephrotic syndrome associated with hepatointestinal schistosomiasis. Revista do Instituto de Medicina Tropical de São Paulo 34:273-276, 1992.

2. Aggio MC. Dacie's syndrome and other splenomegalies of unknown origin. La Revista de Investigation Clinica 42:142-144, 1990.

3. Alves-Brilo CF, Simpson AJG, Bahia-Oliveira MG, Rabello ALT, Rocha RS, Lambertucci JR, Gazzinelli G, Katz N, Correa-Oliveira R. Analysis of anti-keyhole limpel hemocyanin antibody in Brazilians supports its use for the diagnosis of acute schistosomiasis mansoni. Transactions of the Royal Society of Tropical Medicine and Hygiene $86: 53-56,1992$.

4. Amaral RS, Porto MAS. Evolução e situação atual do controle da esquistossomose no Brasil. Revista da Sociedade Brasileira de Medicina Tropical 27 (Supl III) :75-90, 1994.

5. Barbosa FS, Coimbra CEA. Alternative approaches in the schistosomiasis control. Memorias do Instituto Oswaldo Cruz 87 (Supl IV):215-220, 1992.

6. Barbosa MM. Avaliação dopplerecocardiografica do acomelimento cardiopulmonar na esquistossomose mansônica: estudo em area endêmica. Tese de Mestrado, Universidade Federal de Minas Gerais, Belo Horizonte, MG, 1994.

7. Barkun AN, Camus M, Green L, Meagher T, Coupal L, Stempel J, Grover SA. The bedside assessment of splenic enlargement. American Journal of Medicine 91:512-518, 1991 .
8. Bina JC, Andrade ZA, Dietze R, Prata, A. A field study of proteinuria in individuals infected with Schistosoma mansoni. Revista da Sociedade Brasileira de Medicina Tropical 18:7-10, 1985.

9. Coura JR, Mendonça MZG, Madruga JP. Tentativa de avaliação do Programa Especial de Controle da Esquistossomose (PECE) no Estado da Paraiba, Brasil. Revista da Sociedade Brasileira de Medicina Tropical 20:67-76, 1987.

10. Cavalcanti IL, Thompson G, Souza N, Barbosa FS. Pulmonary hypertension in schistosomiasis. British Heart Journal 24:363-371, 1962.

11. Gerspacher-Lara R. Fatores associados a alterações urinárias em uma área hiperendêmica para esquistossomose mansônica: estudo clinico e ultra-sonográfico. Tese de Mestrado, Universidade Federal de Minas Gerais, Belo Horizonte, MG, 1994.

12. Guimarães AC. Situação atual dos conhecimentos sobre o envolvimento cardiopulmonar na esquistossomose mansônica. Arquivos Brasileiros de Cardiologia 38:301$309,1982$.

13. Jenkins JM, Hatz C. The use of diagnostic ultrasound in schistosomiasis-atlempts at standardization of methodology (Meeting on ultrasonography in schistosomiasis, Cairo, Egypi 1991). Acta Tropica 51:45-63, 1992.

14. Jordan P. Schistosoniasis: The St Lucia Project. Cambridge University Press, Cambridge, 1985.

15. Katz N, Rocha RS, Pereira JP. Schistosomiasis control in Peri-Peri(Minas Gerais, Brazil) by repeat clinical treatment and molluscicide application. Revista do Instituto de 
Lambertucci JR, Gerspacher-Lara R, Pinto-Silva RA, Barbosa MM. Teixeira K, Barbosa HF, Serufo JC, Rezende IF, Drummond SC, Rayes AAM. O Projeto Queixadinha: a morbidace o conirole a esquistossomose em drea - ndêmica no nordeste de Minas Gerais, Brasil. Revista da Sociedade Brasileira de Medicina Tropical 29:127-135, nar-abr, 1996.

Medicina Tropical de São Paulo 22 (Supl 4):84-93, 1980.

6. Lambertucei JR. Schistosoma mansoni: pathological and dinical aspects. In: Jordan P, Webbe G, Sturrock RF (eds) Human Schistosomiasis, Cab Internationai, Wallingford, p. $395-235,1993$.

17. Lamberucci JR, Barraviera B. Esquistossomose mansönica: ostudo cínico. Jornal Brasileiro de Medicina 67:59-100, 9994.

i8. LambertuccilR, Godoy P, Neves \, Bambirra EA, Ferreira MD. Glomerulonephritis in Salmaneila-S. mansoni association. American Journai of Tropical Medicine and Hygiene 38:97-102, 1988.

19. Lambertucci JR, Pinto-Silva RA, Gerspacher-Lara R, Barata, CH. Acute Manson's schistosomiasis: sonographic features. Transactions of the Royal Society of Tropical Medicine and Hygiene 88:76-77, 1994.

20. Lambertucci JR, Rabello ALT, Godoy P. A lesāo renal na esquistossomose e na associação Salmonella-S. mansoni. Anais da Facuidade de Medicina da Universidade Federal de Minas Gerais 35:49-60, 1986.

21. Lambertucci JR, Rocha, RS, Carvalho, OS, Katz N. A esquistossomose em Minas Gerais. Revista da Sociedade Brasileira de Medicina Tropical 20:47-52, 1987.

22. Lambertucci JR, Greco DB, Pedroso, ERP, Rocha MOC, Salazar HM, Lima DP. A double blind irial with oxamniquine in chronic wchistosomiasis mansoni. Transactions of the Royal Society of Tropical Medicine and Hygiene 76:751-755, 1982.

23. Lehman JS, Mott KE, Souza CAM, Leboreiro O. Muniz TM. The association of schistosomiasis mansoni and proteinuria in an endemic area. The American Journal of Tropical Medicine and Hygiene 24:616-618, 1975.

24. Machado PA. The brazilian programme for schistosomiasis control, 1975-1979. The American Journal of Tropical Medicine and Hygiene 31:76-86, 1982.

25. Mclntyre OR. Ebaugh FG. Palpable spleens in coilege freshmen. Annals of Internal Medicine 66:301-306, 1967.
26. Nishimura KA. Abel MD, Hatle LK, Tajik AY. Assessment of diastolic function of the heart: background and current applications of dopplerechocardiography. Part II. Clinical studies. Mayo Clinicai Proceedings 64:181-204, 1989

27. Nooman 2M, Hassan AH, Mishrirky AM, Ragheb $M$, Abu-Saif AN. Abaza SM, Serwah AA, Kamal M, Fouad $M$. The use and limitations of ultrasonography in the diagnosis of liver morbidity atributable to Schistosoma nansoni intection in community-based surveys. Memórias do Instituto Oswaldo Cruz 90:147-154, 1995.

28. Pinto-Silva RA, LambertucciJR. O valor da ultra-sonografia na avaliação da esquistossomose mansonj hepatoesplênica. Anais da. Faculdade de Medicina da Universidade Federal de Minas Gerais 35:28-38, 1986.

29. Pinto-Silva RA, Abrantes WL, Artunes CMF, Lambenucei IR. Sonographic features of portal hypertension in schistosomiasis mansoni. Revista do lnstituto de Medicina Tropical de São Paulo 36:355-361, 1994.

30. Prata A. Andrade ZA. Fibrose hepatica de Symmers sem asplenomegalia. O Hospital 63:617-623, 1963.

31. Rabello ALT, Lambertucei JR, Freire MH, Garcia MMA, Amorim MN, Katz N. Evaluation of proteinuria in an area of Brazil endemic for schistosomiasis using a single urine sample. Transactions of the Royal Society of Tropical Medicine and Hygiene 87:187-189, 1993

32. Sullivan S, Wiiliams R. Reliability of clinical techniques for detecting splenic enlargemen. British Medical Journal 2:1043-1044, 1976.

33. Telle RL, Share JC. Ultrasonography in infants and children. WB Saunders, Philadelphia, 1991.

34. Verweij JJ, Polderman AM, Visser LG, Deelder AM. Measurement of antibody response to keyhole limpet haemocyanin was not adequate for early diagnosis of schistosomiasis in a group of Dutch visitors to Mali. Transactions of the Royal Society of Tropical Medicine and Hygiene 89:48-50, 1995 